\title{
Studi Perbandingan Ketelitian Nilai Azimut Melalui Pengamatan Matahari dan Global Positioning System (GPS) Terhadap Titik BM Referensi
}

\section{(Studi Kasus: Kampus ITS Sukolilo)}

\author{
Mohammad Luay Murtadlo dan Yuwono \\ Jurusan Teknik Geomatika, Fakultas Teknik Sipil dan Perencanaan, Institut Teknologi Sepuluh Nopember (ITS) \\ Jl. Arief Rahman Hakim, Surabaya 60111 Indonesia \\ e-mail: yuwono@geodesy.its.ac.id
}

\begin{abstract}
Abstrak- Azimut merupakan hal yang tidak dapat diabaikan dalam melakukan penentuan sebuah posisi. Padahal, pekerjaanpekerjaan yang menyangkut kemampuan disiplin ilmu geodesi membutuhkan suatu penentuan azimut. Prinsip dalam menentukan azimut ada beberapa cara, antara lain dengan melakukan pengamatan benda-benda langit, yang umum dilakukan ialah terhadap matahari dan bintang. Selain itu dengan dua titik pengukuran yang sudah diketahui koordinatnya, dimana koordinat diperoleh dengan melakukan pengukuran menggunakan pengamatan Global Positioning System (GPS). Tujuan dalam penelitian ini, adalah untuk mengetahui berapa ketelitian nilai azimut yang diperoleh dari pengamatan matahari dan pengamatan GPS. Nilai azimut pengamatan GPS lebih teliti daripada pengamatan tinggi matahari yang dibandingkan terhadap nilai azimut dari 2 titik BM referensi.
\end{abstract}

Kata Kunci-Azimut, Tinggi Matahari, Global Positioning System (GPS) .

\section{PENDAHULUAN}

$\mathrm{S}$ EJAK ratusan tahun yang lalu peradaban manusia sudah menggunakan benda-benda langit seperti matahari dan bintang untuk menentukan posisi suatu titik. Para pelaut mulamula,menggunakan gugusan bintang-bintang dilangit sebagai papan penunjuk jalan. Jauh sesudah itu seorang astronomer dan matematikawan berkebangsaan Arab, Al-Khwarizmi dengan teori aljabarnya, pada tahun 800-an membuat model matematik untuk menentukan posisi dengan rumus yang sekarang dikenal dengan ilmu ukur sudut atau trigonometri. Semenjak itulah orang melakukan pengamatan bintang yang lebih akurat untuk menentukan posisi kapal di malam hari dan sekaligus juga pembuatan peta. Dalam melakukan penentuan posisi, tidak dapat mengabaikan yang namanya azimut. Padahal, pekerjaan-pekerjaan yang menyangkut kemampuan disiplin ilmu geodesi membutuhkan suatu penentuan azimut.[1]

Prinsip dalam menentukan azimut ada beberapa cara, antara lain dengan melakukan pengamatan benda-benda langit, yang umum dilakukan ialah terhadap matahari dan bintang. Selain itu dengan dua titik pengukuran yang sudah diketahui koordinatnya,[2] dimana koordinat diperoleh dengan melakukan pengukuran menggunakan pengamatan Global Positioning System (GPS). Adapun dalam pengamatan matahari terdapat banyak metode antara lain metode tinggi matahari, metode sudut waktu, dan metode pengamatan matahari pada tinggi yang sama [3]. Sedangkan dalam pengamatan GPS banyak metode yang dapat digunakan, antara lain absolut, diferensial, post-processing, statik, pseudo-kinematik, kinematik, statik singkat, stop-and-go,dan real time [4].

Pada penelitian ini metode digunakan untuk pengamatan matahari menggunakan metode tinggi matahari, sedangkan untuk pengamatan GPS menggunakan metode diferensial yang diikatkan di titik CORS (Continuously Operating Reference Stations) ITS. Metode tinggi matahari dipilih karena memiliki keunggulan pengamatannya dapat dilakukan saat waktu pagi dan sore. Dan metode diferesial dipilih karena memiliki keunggulan dapat mengeliminir atau mereduksi pengaruh dari beberapa kesalahan dan bias [4].

\section{METODE PENELITIAN}

\section{A. Lokasi Penelitian}

Penelitian tugas akhir ini dilakukan di lokasi kampus Institut Teknologi Sepuluh Nopember (ITS) Sukolilo, Surabaya, Jawa Timur. Terdiri dari 4 titik BM yang masing masing terletak di PRF Lab. Rekayasa Forensik, GPS 3 DESPRO, PPR Gedung Pusat Robotika dan PLE Lab. Energi.

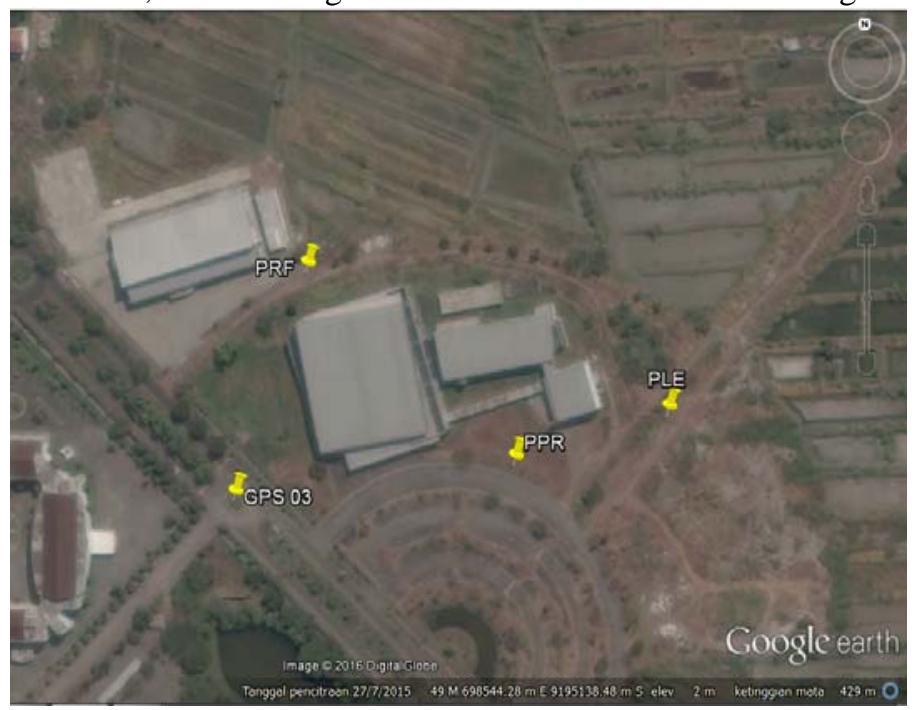

Gambar 1. Lokasi Penelitian 


\section{B. Data dan Peralatan}

1) Data

Data yang digunakan dalam penelitian tugas akhir ini yaitu data pengukuran sudut horisontal dan vertikal matahari, nilai deklinasi matahari, koordinat BM referensi, dan tabel almanak matahari.

2) Peralatan

Peralatan yang digunakan dalam penelitian ini adalah :

1. Perangkat Keras (Hardware)
a) EDT SOKKIA DT510A
b) GPS Geodetik, Dual Frequency Topcon Hiperpro
c) Statif
d) Prisma Roulof
e) Prisma
f) Tribarch
g) Form ukur
h) Laptop Hp Pavilion dm4
i) Termometer
j) Barometer

2. Perangkat Lunak (Software)

a) Microsoft Office 2010

b) Topcon Tools

\section{Tahapan Pengolahan Data}

Secara garis besar tahapan dari pengolahan data yang dilakukan adalah seperti pada diagram alir sebagai berikut :

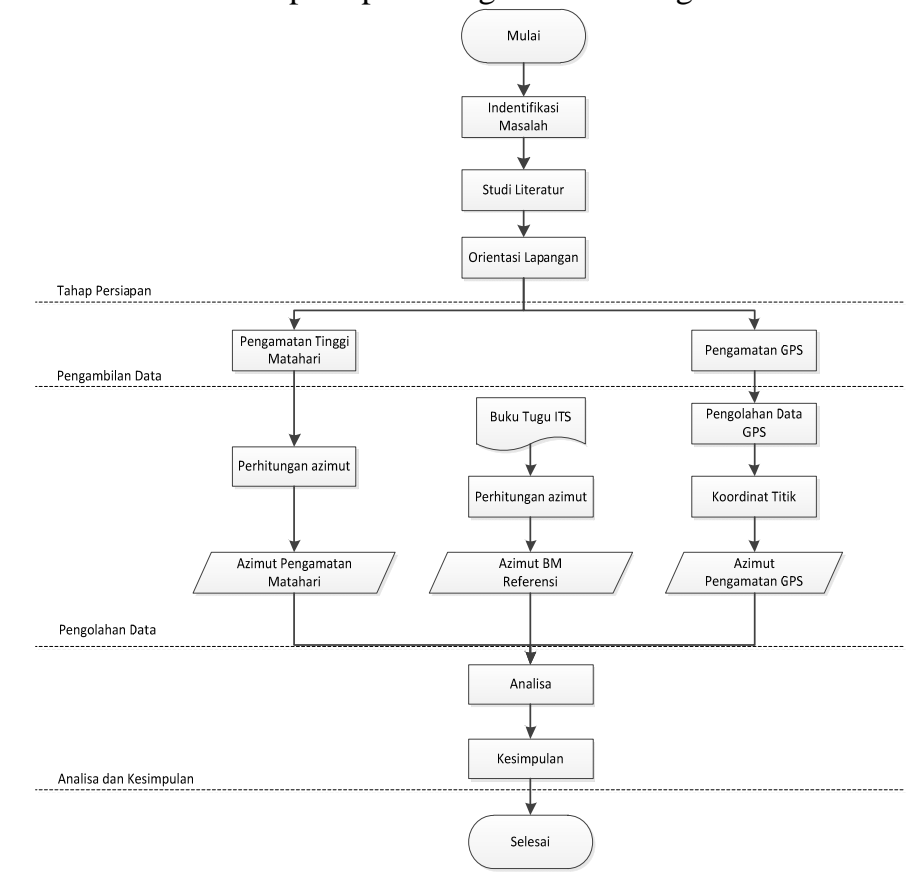

Gambar 2. Diagram Alir Tahapan Penelitian

Berikut adalah penjelasan metode penelitian :

1) Tahap Persiapan

a. Identifikasi Masalah dalam penelitian ini adalah bagaimana proses pengukuran dan pengolahan data pada pengamatan matahari dan GPS.

b. Studi Literatur

Bertujuan untuk mendapatkan referensi yang berhubungan dengan penentuan azimut, metode tinggi matahari, metode diferensial dan literatur lain yang mendukung baik dari buku, jurnal, makalah dan internet.

c. Orientasi Lapangan

Orientasi lapangan yang dimaksud adalah orientasi keadaan topografi lokasi yang akan diukur untuk memperoleh data tugas akhir.

2) Pengambilan Data

a. Pengamatan Tinggi Matahari

Pengamatan dilakukan sore hari dan tahapan ini dilakukan pengambilan data yang berkaitan, antara lain:

- Data bacaan sudut horisotal dan vertikal dari posisi bintang.

- Data suhu udara (dalam ${ }^{\circ} \mathrm{C}$ ), tekanan udara (dalam $\mathrm{mmHg}$ ), dan waktu pengamatan.

b. Pengamatan GPS

Pengamatan dilakukan dengan metode diferensial, dimana setiap sesi memiliki lama waktu pengamatan yang berbeda.

3) Pengolahan Data

a. Pengolahan data dari pengamatan tinggi matahari.

Pada pengolahan ini terdiri koreksi data, perhitungan deklinasi matahari, lintang pengamat, perhitungan azimut matahari, perhitungan azimut titik acuan dan perhitungan ketelitian pengamat. Perhitungan azimut pengamatan tinggi matahari dapat dijabarkan seperti gambar berikut:

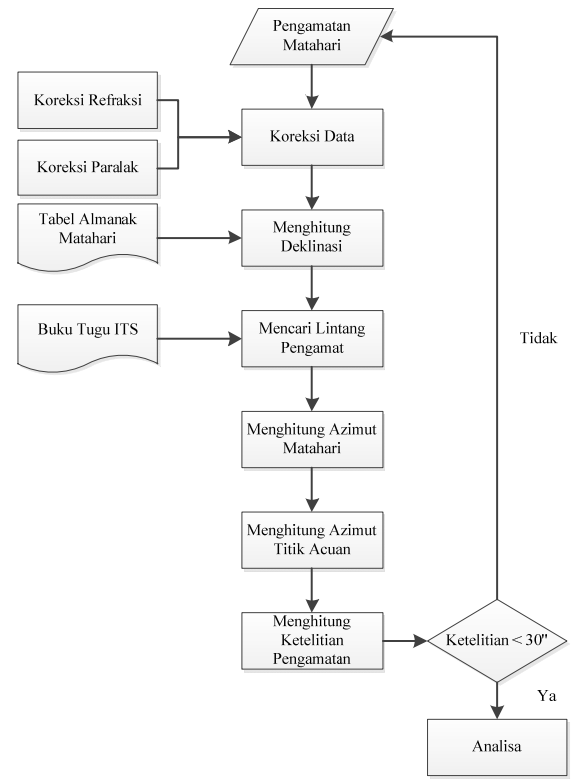

Gambar 3. Proses Perhitungan Azimut Pengamatan Tinggi Matahari

- Koreksi Data

- Menghitung Deklinasi

- Mencari Lintang Pengamat

- Menghitung Azimut Matahari

- Menghitung Azimut Titik Acuan

- Menghitung Ketelitian Pengamatan 
b. Pengolahan data dari pengamatan GPS

Pada pengolahan ini menggunakan software Topcon Tools dan hasilnya berupa koordinat titik. Dari koordinat titik, dapat dihitung azimut.

c. Pengolahan dari Buku Tugu ITS

Pada pengolahan dari buku tugu ITS bertujuan untuk mendapatkan nilai azimut BM referensi. Dimana Azimut BM referensi merupakan data yang dianggap benar.

\section{4) Analisa dan Kesimpulan}

Tahap ini dimaksudkan untuk menganalisa dan membandingkan nilai azimut pengamatan matahari dan pengamatan GPS terhadap azimut BM referensi. Analisa ini diperoleh dari data yang telah diolah pada tahap sebelumnya. Sehingga didapatkan suatu hasil dan kesimpulan yang nantinya digunakan untuk menyusun laporan tugas akhir.

\section{HASIL DAN ANALISA}

\section{A. Perhitungan Azimut Metode Tinggi Matahari}

Tabel 1.

Hasil perhitungan azimut dengan metode tinggi matahari PRF - GPS03

\begin{tabular}{lcccc}
\hline \hline Pengamatan & \multicolumn{3}{c}{ Azimut PRF - GPS03 } & $\begin{array}{l}\text { Standar } \\
\text { Deviasi } \\
\text { (Detik) }\end{array}$ \\
\hline Sesi 1 & Derajat & Menit & Detik & 23,95 \\
Sesi 2 & 197 & 52 & 56,28 & 11,50 \\
\hline \hline
\end{tabular}

Tabel 2.

Hasil perhitungan azimut dengan metode tinggi matahari GPS03 - PPR

\begin{tabular}{lcccc}
\hline \hline \multirow{2}{*}{ Pengamatan } & \multicolumn{3}{c}{ Azimut GPS03 - PPR } & $\begin{array}{l}\text { Standar } \\
\text { Deviasi } \\
\text { (Detik) }\end{array}$ \\
\hline Sesi 1 & Derajat & Menit & Detik & 18,88 \\
Sesi 2 & 86 & 35 & 2,94 & 19,92 \\
\hline \hline
\end{tabular}

Tabel 3.

Hasil perhitungan azimut dengan metode tinggi matahari PPR - PLE

\begin{tabular}{lcccc}
\hline \hline \multirow{2}{*}{ Pengamatan } & \multicolumn{3}{c}{ Azimut PPR - PLE } & $\begin{array}{c}\text { Standar } \\
\text { Deviasi } \\
\text { Sesi 1 }\end{array}$ \\
Derajat & Menit & Detik & (Detik) \\
\hline Sesi 2 & 75 & 30 & 7,15 & 26,3 \\
\hline \hline
\end{tabular}

\section{B. Azimut Pengamatan GPS}

Pada pengamatan Global Positioning System (GPS), pengamatan dilakukan sebanyak 2 sesi dengan interval yang berbeda, antara lain pada interval 30 menit, 1 jam, dan 2 jam. Hasil pengamatan dan azimut yang diperoleh dari pengamatan GPS, sebagai berikut :

\section{1) Interval 30 menit}

Tabel 4.

Azimut Interval 30 Menit sesi 1

\begin{tabular}{lrrr}
\hline \multirow{2}{*}{ Nama } & \multicolumn{3}{c}{ Azimut } \\
& Derajat & Menit & Detik \\
\hline PRF-GPS03 & 197 & 54 & 55,30 \\
GPS03-PPR & 86 & 40 & 15,28 \\
PPR-PLE & 75 & 34 & 47,22 \\
\hline \hline
\end{tabular}

Tabel 5.

Azimut Interval 30 Menit sesi 2

\begin{tabular}{lrrr}
\hline \hline \multirow{2}{*}{ Nama } & \multicolumn{3}{c}{ Azimut } \\
& Derajat & Menit & Detik \\
\hline PRF-GPS03 & 197 & 54 & 58,78 \\
GPS03-PPR & 86 & 40 & 15,42 \\
PPR-PLE & 75 & 34 & 49,02 \\
\hline \hline
\end{tabular}

2) Interval 1 jam

Tabel 6.

Azimut Interval 1 Jam sesi 1

\begin{tabular}{lrrr}
\hline \multirow{2}{*}{ Nama } & \multicolumn{3}{c}{ Azimut } \\
& Derajat & Menit & Detik \\
\hline PRF-GPS03 & 197 & 55 & 00,80 \\
GPS03-PPR & 86 & 40 & 16,48 \\
PPR-PLE & 75 & 34 & 44,10 \\
\hline \hline
\end{tabular}

Tabel 7.

Azimut Interval 1 Jam sesi 2

\begin{tabular}{lrrr}
\hline \hline \multicolumn{1}{c}{ Nama } & \multicolumn{3}{c}{ Azimut } \\
& Derajat & Menit & Detik \\
\hline PRF-GPS03 & 197 & 55 & 00,01 \\
GPS03-PPR & 86 & 40 & 16,54 \\
PPR-PLE & 75 & 34 & 40,95 \\
\hline \hline
\end{tabular}

3) Interval 2 jam

Tabel 8.

Azimut Interval 2 Jam

\begin{tabular}{lrrr}
\hline \multicolumn{1}{c}{ Nama } & \multicolumn{3}{c}{ Azimut } \\
& Derajat & Menit & Detik \\
\hline PRF-GPS03 & 197 & 55 & 00,80 \\
GPS03-PPR & 86 & 40 & 14,18 \\
PPR-PLE & 75 & 34 & 42,51 \\
\hline \hline
\end{tabular}

Tabel 9.

Azimut Interval $2 \mathrm{Jam}$

\begin{tabular}{lrrr}
\hline \multicolumn{1}{c}{ Nama } & \multicolumn{3}{c}{ Azimut } \\
& Derajat & Menit & Detik \\
\hline PRF-GPS03 & 197 & 55 & 00,41 \\
GPS03-PPR & 86 & 40 & 14,21 \\
PPR-PLE & 75 & 34 & 42,79 \\
\hline \hline
\end{tabular}




\section{Azimut BM Referensi}

Dalam buku tugu ITS, terdapat informasi koordinat BM referensi, yang kemudian dihitung azimutnya dari 2 titik BM referensi. Dimana azimut dari 2 titik BM referensi merupakan data yang dianggap benar. Berikut data koordinat BM referensi dan hasil perhitungan azimut dari 2 titik BM referensi:

Tabel 10.

Koordinat BM Referensi

\begin{tabular}{|c|c|c|}
\hline Name & WGS84 Latitude & WGS84 Longitude \\
\hline PRF & $7^{\circ} 16^{\prime} 36,84734^{\prime \prime S}$ & $112^{\circ} 47^{\prime} 49,76012^{\prime \prime} \mathrm{E}$ \\
\hline PLE & $7^{\circ} 16^{\prime} 39,10445^{\prime \prime S}$ & $112^{\circ} 47^{\prime} 55,15704^{\prime \prime E}$ \\
\hline GPS03 & $7^{\circ} 16^{\prime} 39,90502 " \mathrm{~S}$ & $112^{\circ} 47^{\prime} 48,77006^{\prime \prime} \mathrm{E}$ \\
\hline PPR & 7¹6'39,65959"S & $112^{\circ} 47^{\prime} 52,99508^{\prime \prime} \mathrm{E}$ \\
\hline ITS CORS & $7^{\circ} 16^{\prime} 47,95465^{\prime \prime S}$ & $112^{\circ} 47^{\prime} 40,65034^{\prime \prime E}$ \\
\hline
\end{tabular}

Tabel 11.

Azimut BM Referensi

\begin{tabular}{cccc}
\hline \hline Nama & Derajat & $\begin{array}{c}\text { Azimut } \\
\text { Menit }\end{array}$ & Detik \\
\hline PRF-GPS03 & 197 & 56 & 30 \\
GPS03-PPR & 86 & 40 & 31,6 \\
PPR-PLE & 75 & 35 & 56,04 \\
\hline \hline
\end{tabular}

D. Analisa Nilai Azimut Pengamatan Matahari dan GPS Terhadap BM Referensi

Tabel 12.

Hasil Perbandingan Nilai Azimut Melalui Pengamatan Matahari

\begin{tabular}{ccccc}
\hline $\begin{array}{c}\text { Pengamatan } \\
\text { Azimut }\end{array}$ & Derajat & $\begin{array}{c}\text { Azimut } \\
\text { Menit }\end{array}$ & Detik & $\begin{array}{c}\text { RMSE } \\
\text { (Detik) }\end{array}$ \\
\hline \multirow{2}{*}{ PRF-GPS03 } & 197 & 52 & 56,28 & 52.32 \\
& 197 & 53 & 1,32 & \\
GPS03-PPR & 86 & 35 & 2,94 & 425.99 \\
& 86 & 35 & 23,32 & \\
PPR-PLE & 75 & 30 & 7,15 & 387.2 \\
& 75 & 30 & 10,76 & \\
\hline
\end{tabular}

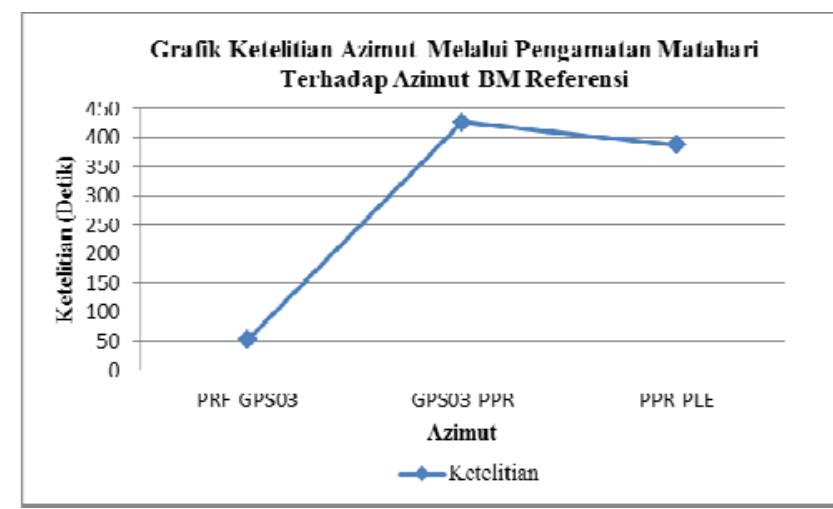

Gambar 4. Grafik Ketelitian Azimut Melalui Pengamatan Matahari Terhadap BM Referensi

Gambar 4. menyatakan hubungan nilai ketelitian azimut melalui pengamatan matahari terhadap azimut BM referensi yang diperoleh pada tabel 12. Dari gambar dapat diambil hasil ketelitian pada azimut PRF-GPS03 adalah 52,32”, pada azimut GPS03-PPR adalah 425,99, dan pada azimut PPR-PLE adalah 387,2 .
Tabel 13.

Hasil Perbandingan Nilai Azimut PRF-GPS03 Melalui Pengamatan GPS

\begin{tabular}{ccccc}
\hline $\begin{array}{c}\text { Interval } \\
\text { Pengamatan }\end{array}$ & Derajat & $\begin{array}{c}\text { Azimut } \\
\text { Menit }\end{array}$ & Detik & $\begin{array}{c}\text { RMSE } \\
\text { (Detik) }\end{array}$ \\
\hline \multirow{2}{*}{30 Menit } & 197 & 54 & 55,3 & 5.63 \\
& 197 & 54 & 58,78 & \\
60 Menit & 197 & 55 & 0,8 & 0.64 \\
& 197 & 55 & 0,01 & \\
120 Menit & 197 & 55 & 0,8 & 0.28 \\
& 197 & 55 & 0,41 & \\
\hline
\end{tabular}

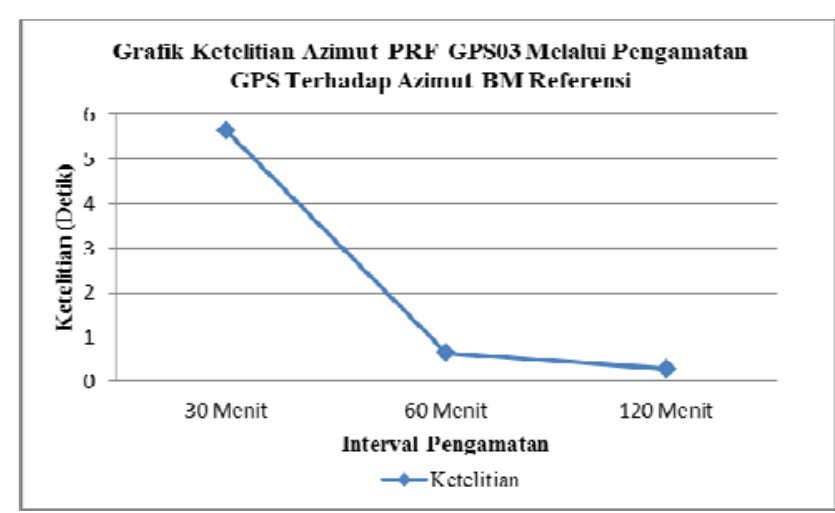

Gambar 5. Grafik Ketelitian Azimut PRF-GPS03 Melalui Pengamatan GPS Terhadap BM Referensi

Gambar 5. menyatakan hubungan nilai ketelitian azimut melalui pengamatan GPS terhadap azimut BM referensi yang diperoleh pada tabel 13. Dari gambar dapat diambil hasil ketelitian pada interval waktu 30 menit adalah 5,63", pada interval waktu 1 jam adalah 0,64", dan pada interval waktu 2 jam adalah $0,28 ”$.

Tabel 14.

Hasil Perbandingan Nilai Azimut GPS03-PPR Melalui Pengamatan GPS

Interval Azimut RMSE

\begin{tabular}{lcccc} 
Pengamatan & Derajat & Menit & Detik & (Detik) \\
\hline \multirow{2}{*}{30 Menit } & 86 & 40 & 15,3 & 3.3 \\
& 86 & 40 & 15,42 & \\
\multirow{2}{*}{60 Menit } & 86 & 40 & 16,48 & 1.67 \\
& 86 & 40 & 16,54 & \\
120 Menit & 86 & 40 & 14,18 & \multirow{2}{*}{0.03} \\
& 86 & 40 & 14,21 & \\
\hline
\end{tabular}

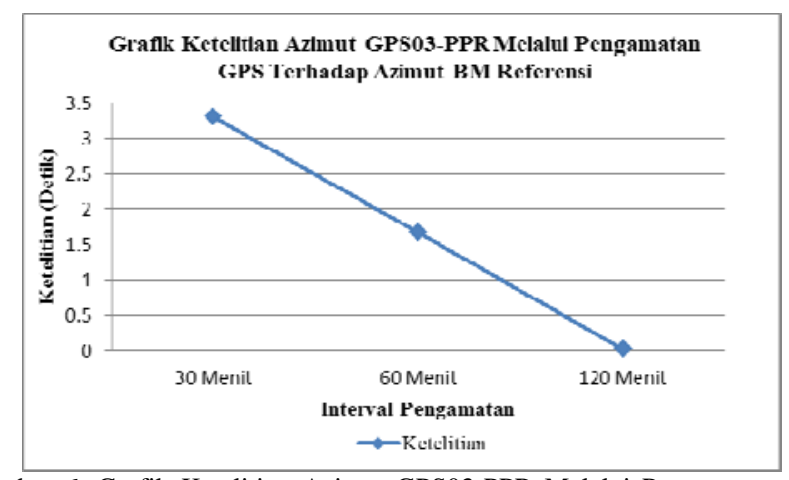

Gambar 6. Grafik Ketelitian Azimut GPS03-PPR Melalui Pengamatan GPS Terhadap BM Referensi 
Gambar 6. menyatakan hubungan nilai ketelitian azimut melalui pengamatan GPS terhadap azimut BM referensi yang diperoleh pada tabel 14. Dari gambar dapat diambil hasil ketelitian pada interval waktu 30 menit adalah 1,67”, dalam interval waktu 1 jam adalah 3,3”, dan pada interval waktu 2 jam adalah 0,03 ".

Tabel 15.

\begin{tabular}{lcccc}
\multicolumn{6}{c}{ Hasil Perbandingan Nilai Azimut PPR-PLE Melalui Pengamatan GPS } \\
$\begin{array}{c}\text { Interval } \\
\text { Pengamatan }\end{array}$ & Derajat & $\begin{array}{c}\text { Azimut } \\
\text { Menit }\end{array}$ & Detik & $\begin{array}{c}\text { RMSE } \\
\text { (Detik) }\end{array}$ \\
\hline \multirow{2}{*}{30 Menit } & 75 & 34 & 47,22 & 7.71 \\
& 75 & 34 & 49,02 & \\
\multirow{2}{*}{60 Menit } & 75 & 34 & 44,1 & 2.25 \\
& 75 & 34 & 40,95 & \\
\multirow{2}{*}{ 120 Menit } & 75 & 34 & 42,51 & 0.23 \\
& 75 & 34 & 42,79 & \\
\hline
\end{tabular}

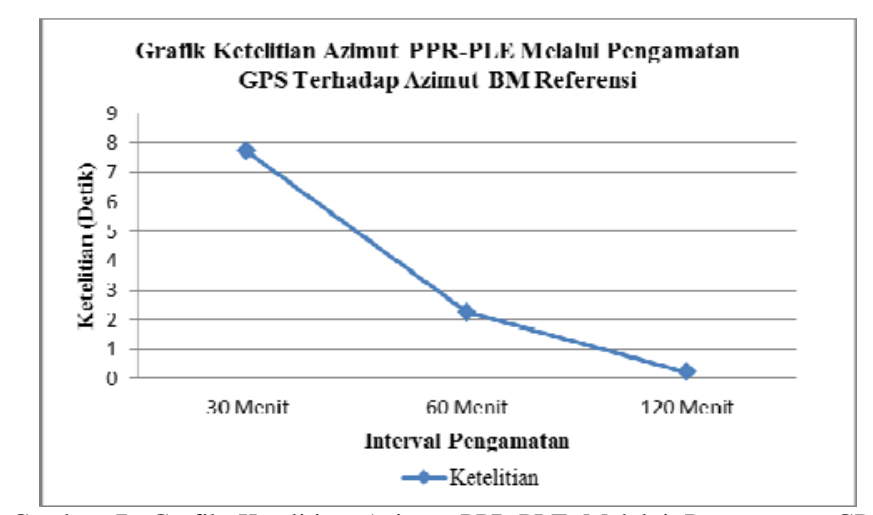

Gambar 7. Grafik Ketelitian Azimut PPR-PLE Melalui Pengamatan GPS Terhadap BM Referensi

Gambar 7. menyatakan hubungan nilai ketelitian azimut melalui pengamatan GPS terhadap azimut BM referensi yang diperoleh pada tabel 15. Dari gambar dapat diambil hasil ketelitian pada interval waktu 30 menit adalah 7,71", dalam interval waktu 1 jam adalah 2,25”, dan pada interval waktu 2 jam adalah $0,23 ”$.

\section{KESIMPULAN}

Kesimpulan yang dapat diambil dari peneliti tugas akhir ini adalah nilai azimut pengamatan GPS lebih teliti daripada pengamatan tinggi matahari yang dibandingkan terhadap nilai azimut dari 2 titik BM referensi. Ketelitian nilai azimut pengamatan tinggi memiliki rata-rata sebesar 4 menit 48,5 detik. Sedangkan ketelitian nilai azimut pengamatan GPS memiliki rata-rata sebesar 7,24 detik.

\section{DAFTAR PUSTAKA}

[1] Prawiro, Yoel., Taufik, M., dan Muhamdi, Mansur., "Penentuan Azimut Pada Pengamatan Bintang Dengan Metode Diurnal Circle”.

[2] AS, Supardjo., Sudarmadi., Widito, P., dan Sudarto, Slamet., 2000. "Penentuan Azimut Matahari dalam Pemetaan Topografi di Rirang Kalimantan”. Prosiding Seminar Pranata Nuklir dan Teknisi Litkayasa P2BGN - BATAN, Jakarta, 8 Maret 2000.

[3] Kartawiharja, Ir. S. Basuki. 1988. Penentuan Azimuth Dengan Pengamatan Matahari. Kanisius. Jogjakarta.
[4] Abidin, Hasanuddin. 2007. Penentuan Posisi dengan GPS dan Aplikasinya. Jakarta: Pradnya Paramita. 